\title{
Comparative Study of the Possible Effect of Bovine and Some Plant-Based Milk on Cola-Induced Enamel Erosion on Extracted Human Mandibular First Premolar
}

\author{
Nehad M Abd-Elmonsif ${ }^{*}$, Medhat A El-Zainy ${ }^{2}$ and Marwa M Abd-Elhamid ${ }^{2}$ \\ ${ }^{1}$ Department of Oral Biology, Future University, Egypt \\ ${ }^{2}$ Oral Biology, Faculty of Dentistry, Ain-Shams University, Egypt
}

Submission: June 16, 2017; Published: July 21, 2017

*Corresponding author: Nehad M Abd-Elmonsif, Department of Oral Biology, Faculty of Dentistry, Future University, Egypt,

Email: noda2055@yahoo.com

\begin{abstract}
Increased consumption of acidic soft drinks is becoming an important factor in the development of erosive wear. The potential of dairy drinks to protect enamel against dental erosion has been recorded. Recently, the demand for plant based milk beverages has been gaining popularity and used as an alternative to cow's milk.
\end{abstract}

Aim: reveal and compare the possible effects of bovine and three types of plant-based milk on enamel erosion caused by Coca-Cola ${ }^{\circledR}$.

Material and Methods: 42 extracted premolars were distributed over three groups: Control negative group where teeth were not subjected to any treatment, Control positive group where teeth were subjected to Coca-Cola ${ }^{\circledR}$ and Experimental group where teeth were divided into four subgroups and subjected to Coca-Cola ${ }^{\circledR}$ then soaked in certain type of milk (bovine, soy, almond or oat milk). All groups were prepared for SEM analysis and EDAX.

Results: Coca-Cola $®$ beverage significantly altered enamel superficial surface structure causing irregular surface, erosive lesions and cracks .Bovine and plant based milk has a reparative effect on eroded cervical buccal enamel.

Conclusion: Almond milk showed better results than other types of milk used concerning Ca and P levels as well as surface morphological alternations. Soy milk showed the least enamel remineralizing effect.

Keywords: Dental erosion; Coca-Cola ${ }^{\circledR}$, Bovine milk; Soy milk; Almond milk; Oat milk

\section{Introduction}

Dental erosion is defined as a loss of dental hard tissue caused by acids, without bacterial involvement. Erosion may be caused by intrinsic or extrinsic factors. The extrinsic factors are related to acidic environment, diet, medication and life style Zero [1] 1996; Magalhaes et al. [2]. Currently, the increased consumption of acidic foods and soft drinks is becoming an important factor in the development of erosive wear Lussi et al. [3], 2004; Lussi and Jaeggi [4] 2006. Coca-Cola $®$, as an example of soft drinks, was the world's most popular brand according to Inter brand's best global brand study of 2011, Houpt and Simon [5], 2011.

On the other hand, some studies showed the potential of dairy foods and drinks to protect enamel against dental Gedalia E et al. [6], 1991 and Lewinstein et al. [7], 1993 showed the rehardeningeffects of cow's milk and cheese in situ following the softening of human enamel with an acidic soft drink (cola drink).

Previous studies by Reynolds et al. [8] 1999 and Morgan et al. [9] 2008 have shown that bovine milk possesses anti-cariogenic properties in animal caries models and can remineralize enamel subsurface lesions in vitro McDougall [10] 1977; Mor and Rodda [11], 1983.

Recently soy, almond and Oat milk are used as an alternative to cow's milk especially for those have milk allergy or lactose intolerance and /or vegetarians. Plants based milk beverages can be made from cereals such as rice and oats, nuts such as almonds and legumes Anonymous [12], 2013. Soy and almond milk are popular examples of non-dairy milks in the USA while oat milk is common in the Europe. These beverages vary in taste and texture 
and are available in different formulations in the market Latif [13], 2012.

The aim of the present study is to reveal and compare the possible effects of bovine milk and three types of plant-based milk on enamel erosion caused by coca-cola on human lower first premolars.

\section{Materials and Methods}

Forty two sound (caries-free) human mandibular first premolars freshly extracted for orthodontic reasons were used in the present study. The extracted teeth were cleaned gently from residual debris and are washed thoroughly under running water and then they were examined under stereomicroscope to ensure the absence of caries, calculus, or surface defects. The apical foramen of each tooth was blocked with water proof acrylic varnish to prevent fluid entrance through it Ehlen et al. [14], 2008 then the teeth were divided into the following groups:

A. Control negative group (C-ve): seven teeth were placed in distilled water during the experimental period.

B. Control positive group $(\mathrm{C}+\mathrm{ve})$ : seven teeth were placed in a beaker filled with $330 \mathrm{ml}$ of Coca-cola ${ }^{\circledR}$ and immersed for $25 \mathrm{hrs}$ and replaced every $5 \mathrm{hrs}$. This model allows for observation of demineralization within a reasonable time period as designed by Ehlen et al. [14], 2008.

C. Experimental group: Twenty eight collected teeth were placed in a beaker filled with $330 \mathrm{ml}$ of Coca-cola ${ }^{\circledR}$ and immersed for $25 \mathrm{hrs}$ and replaced every five hours Ehlen et al. [14], 2008, then they were washed in water for seconds and dried by warm air (McDougall [10], 1977), then they were randomly subdivided into 4 equal subgroups $(7$ premolars each) as follows:

a. Subgroup 1(SG1): 7 teeth were immersed in a beaker filled with $125 \mathrm{ml}$ of bovine milk (JUHAYNA® full cream); for $50 \mathrm{hrs}$ and milk was replaced every 2 hours as designed by McDougall [10], 1977.

b. Subgroup 2 (SG2): 7 teeth were immersed in a beaker filled with $125 \mathrm{ml}$ of Soy milk(Alpro® Soya Original); for $50 \mathrm{hrs}$ and milk was replaced every 2 hours.

c. Subgroup 3 (SG3): 7 teeth were immersed in a beaker filled with $125 \mathrm{ml}$ of almond milk (Alpro® Almond Original); for $50 \mathrm{hrs}$ and milk was replaced every 2 hours.

d. Subgroup 4 (SG4): 7 teeth were immersed in a beaker filled with $125 \mathrm{ml}$ of oat milk(Alpro® Oat Original); for $50 \mathrm{hrs}$ and milk was replaced every 2 hours.

Each tooth was washed under running water for $3 \mathrm{~min}$ and blotted dry in open air then it was mounted on the SEM holder using removable adhesive. The middle of the cervical third of enamel on buccal surface was adjusted to be examined and to measure the surface (Ca) and (P) weight \% using FEI/ Inspect (S) scanning electron microscope attached with energy dispersive X-ray analyzer (SEM-EDXA Unit, Main Defense Chemical Laboratory).
For the scanning electron microscopic examination, the collected teeth were examined at $30 \mathrm{kV}$ using the secondary electron LFD detector under the magnification (X1000) and (X4000) with a (spot size 4.7-5.5nm) in each magnification. Surface (Ca) and (P) weight $\%$ were measured with energy dispersive X-ray analysis (EDXA) with S-UTW detector (EDXA Inc., Mahwah, NJ, USA). The count rates of the EDXA detector were between 1800 and 2000 counts per second .with a resolution of $132.14 \mathrm{eV}$ El-Zainy et al. [15], 2012. Statistical analysis was used for data management and analysis so paired T-test was used to compare the values before and after immersion in different products, one way analysis of variance (ANOVA) followed by Tukey type non-parametric post hoc test are used for multiple comparisons, to determine differences between groups and $\mathrm{Ca}$ and $\mathrm{P}$ contents.

\section{Results}

\section{Histological results}

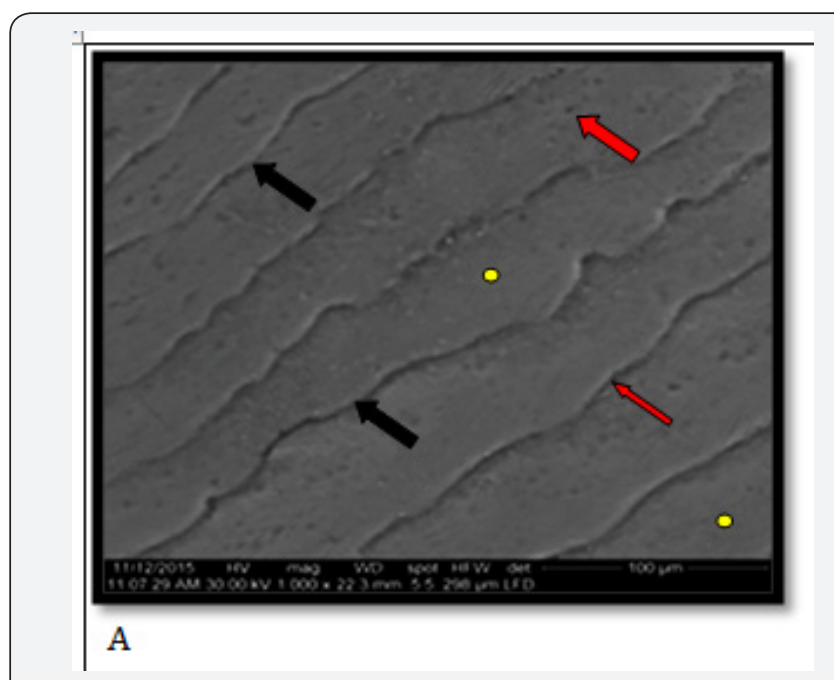

Figure 1: Scanning electron micrographs for cervical buccal enamel showing.A: $\mathrm{C}$-ve group showing perikymata grooves and ridges(Black arrows), few enamel rod ends (Red arrows) and areas of rodless enamel (yellow dots) (x1000).

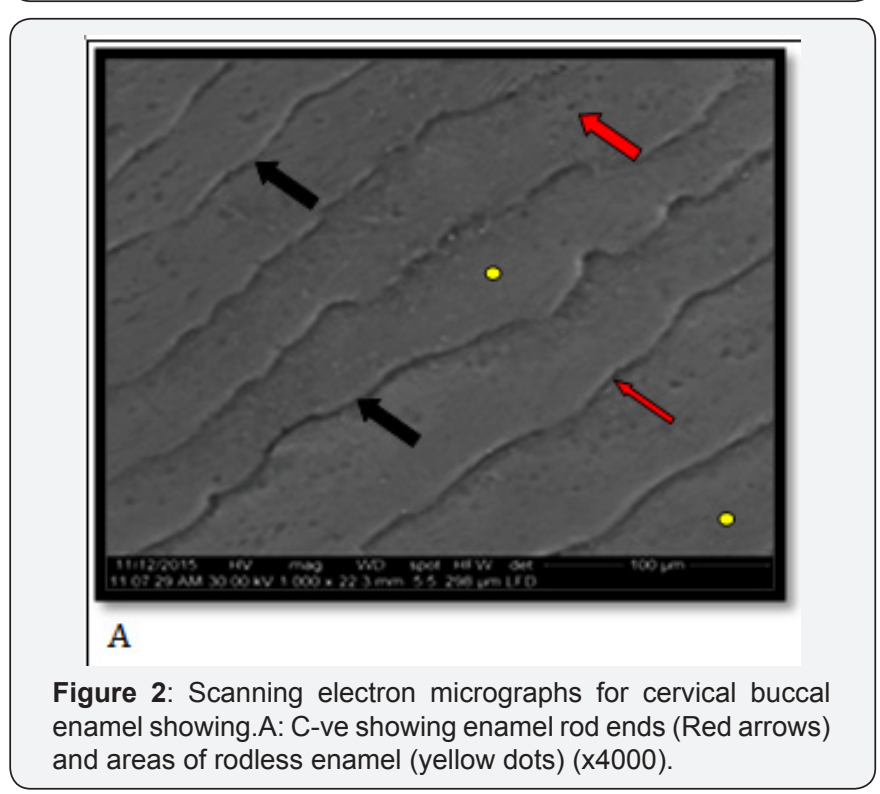


Control -ve group: Examination by SEM of the control -ve group, cervical third of the buccal surface, revealed a smooth regular enamel surface with no evidence of erosive areas, distinctive cracking or any surface defects. A plenty of well-defined perikymata grooves and ridges, few enamel rod ends and areas of rod less enamel are clearly observed (Figure 1A \& 2A).

Control positive group (Cola group): Examination by SEM of the control +ve group, cervical third of the buccal surface, revealed irregular enamel surface with some evidence of erosive lesions, darkened areas of irregular outline and areas of ill-defined enamel structure and apparently observed irregular grooves of variable length (Figure 1B \& 2B).

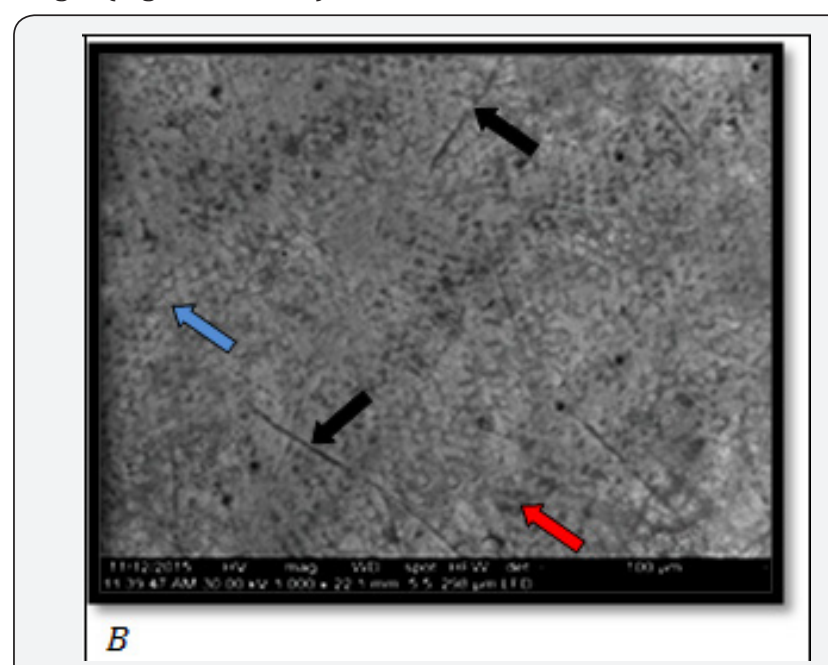

Figure 1: Scanning electron micrographs for cervical buccal enamel showing.B: C +ve group, showing areas of ill-defined enamel structure (blue arrows), irregular grooves of variable length(black arrows) and darkened areas of irregular outline( red arrow) (x1000).

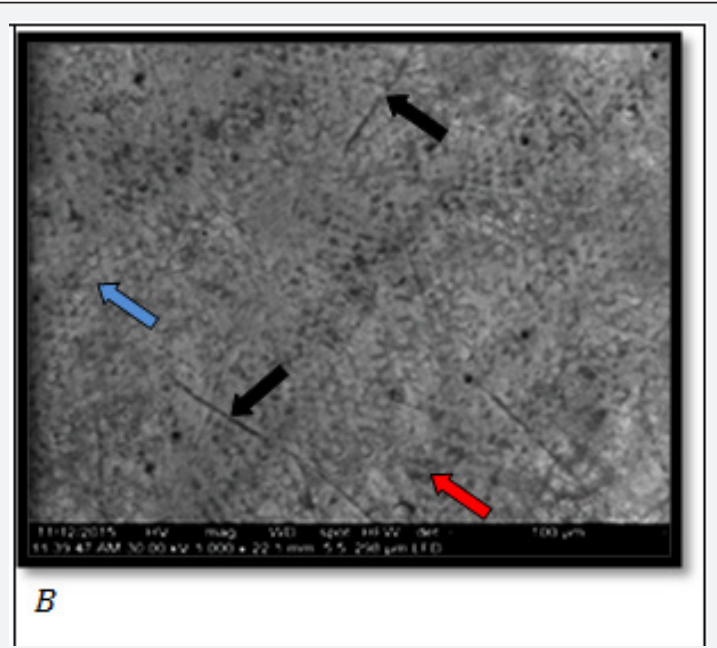

Figure 2: Scanning electron micrographs for cervical buccal enamel showing.B: $C+v e$ group, showing irregular enamel surface with some areas of erosion (black arrows) and areas of ill-defined enamel structure (x4000).

Subgroup 1 (milk group): Examination by SEM of the cervical third of buccal surface in this group, revealed apparent small light sporadic areas with large erosive areas (Figure 1C \& 2C).

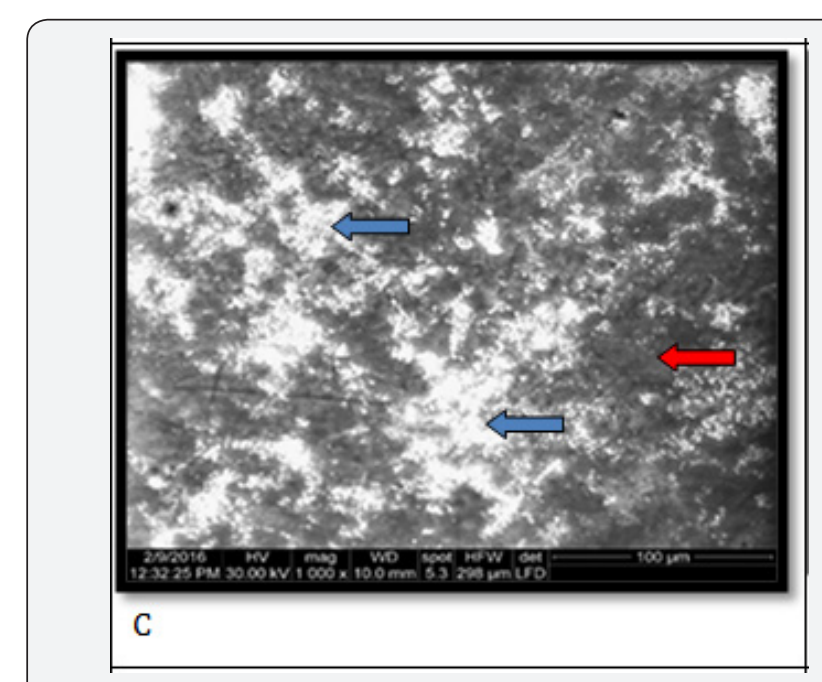

Figure 1: Scanning electron micrographs for cervical buccal enamel showing.C: SG1 showing small light areas (blue arrows) with large erosive area (red arrow) (x1000).

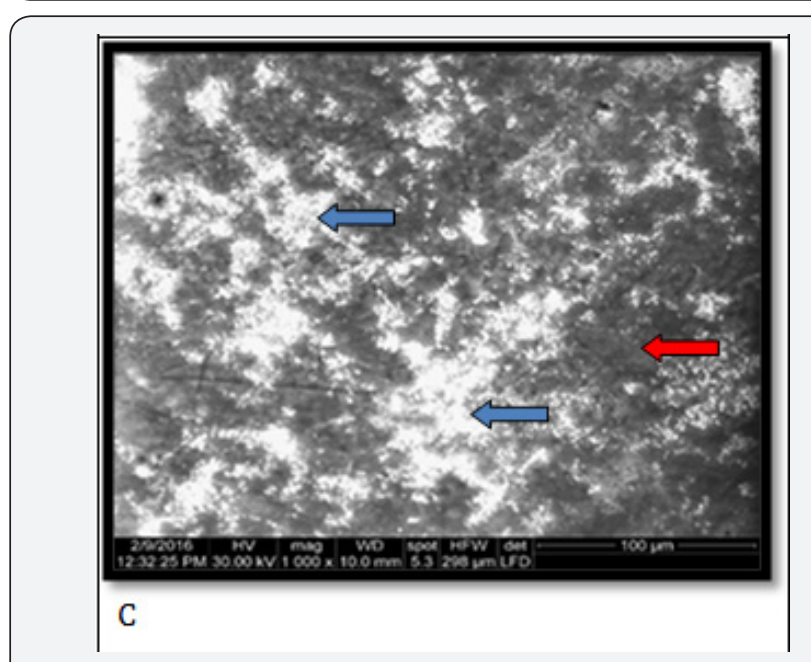

Figure 2: Scanning electron micrographs for cervical buccal enamel showing.C: SG1 showing small light sporadic areas (blue arrows) and large erosive areas (red arrows) (x4000).

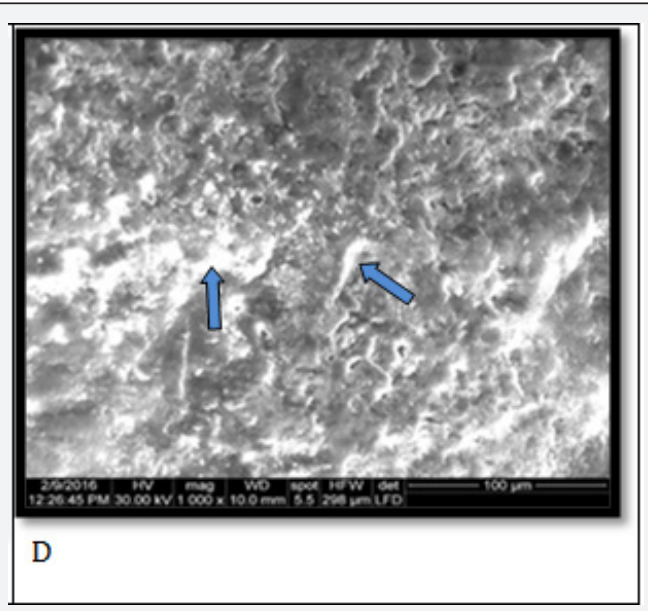

Figure 1: Scanning electron micrographs for cervical buccal enamel showing.D: SG2 showing irregular enamel surface with porous defects seemed to be lined by white deposit (blue arrows) (x1000). 


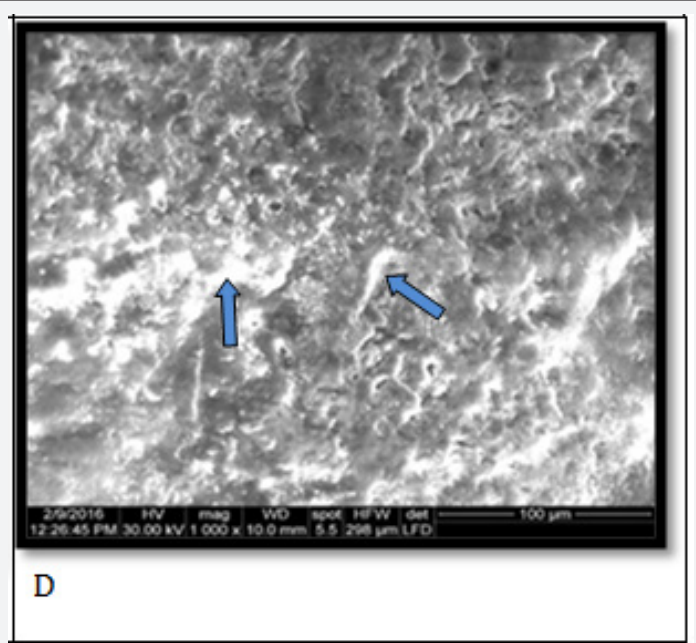

Figure 2: Scanning electron micrographs for cervical buccal enamel showing.D: SG2 showing showing deposits that just seal the irregularities (blue arrows), and minute cracks (red arrows) could be detected $(x 4000)$.

Subgroup 2(soy group): Examination by SEM of cervical third of the buccal surface in this subgroup, revealed irregular enamel surface with porous defects seemed to be lined by white deposits (Figure 1D) and minute cracks could be detected (Figure 2D).

Subgroup 3 (almond group): This subgroup revealed almost regular smooth enamel surface with diffused deposits no obvious cracks, small areas of defect still present (Figure 1E \& 2E).

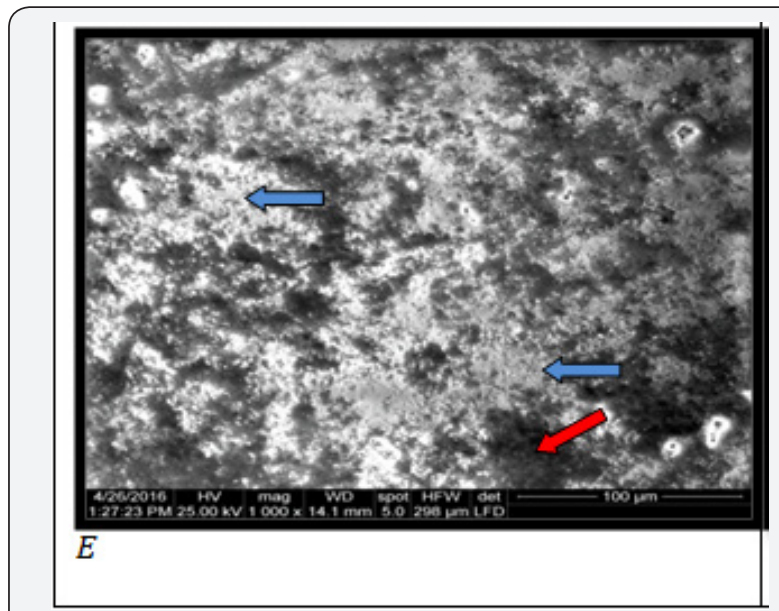

Figure 1: Scanning electron micrographs for cervical buccal enamel showing.E: SG3 showing areas of calcified deposits are seen along porous defects (blue arrows), erosive areas still present (red arrow) (x1000).

Subgroup 4 (Oat group):This subgroup revealed sporadic globular pattern of deposits, recovered erosive enamel surface, deposits on the enamel surface fill the irregularities of the enamel however there are areas of erosive defects still exist (Figure 1F \& $2 \mathrm{~F})$.

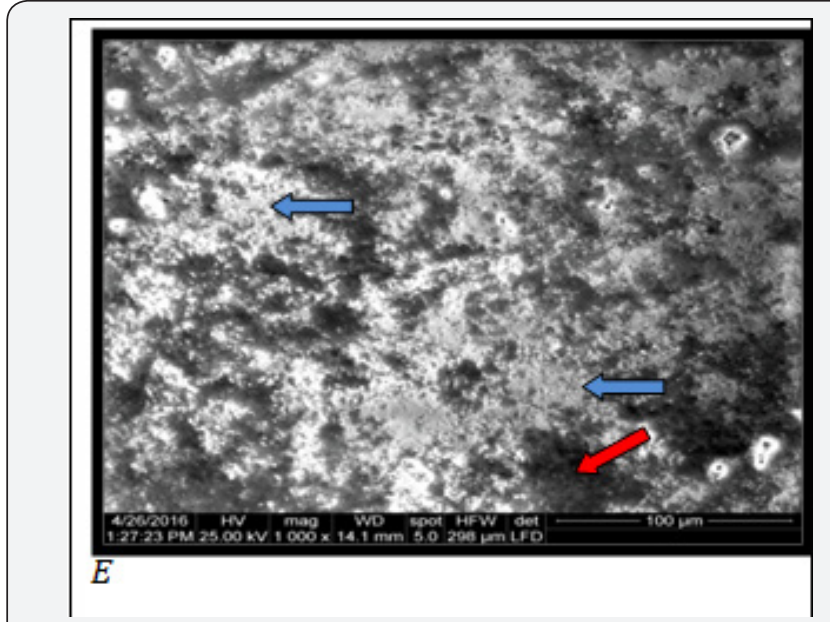

Figure 2: Scanning electron micrographs for cervical buccal enamel showing.E: SG3 showing light areas (blue arrows) profusely scattered along the porous defect (red arrows) (x4000).

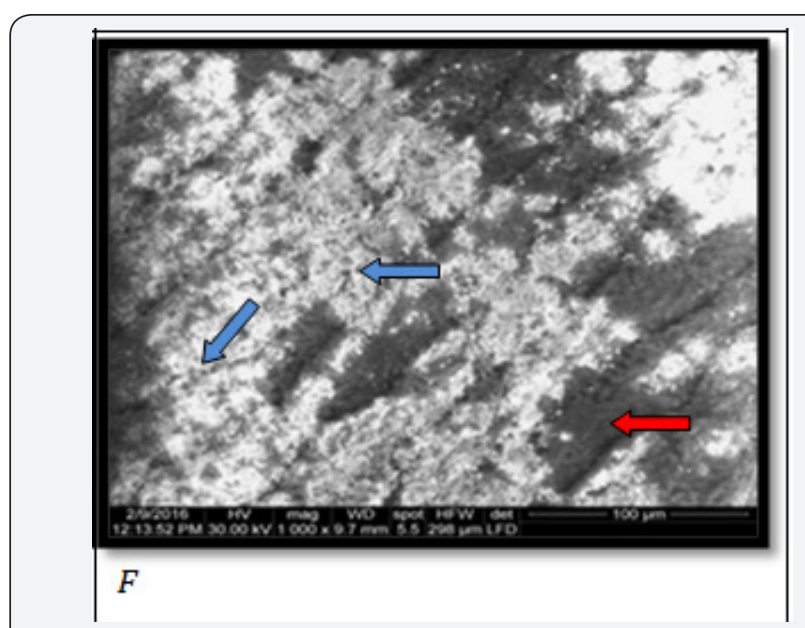

Figure 1: Scanning electron micrographs for cervical buccal enamel showing.F: SG4 revealed areas of globular light deposits (blue arrows) on the enamel surface and areas of erosive defects (red arrow) (x1000).

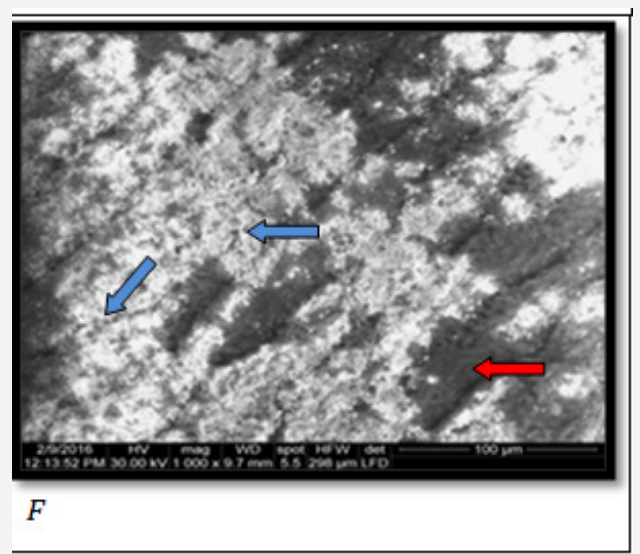

Figure 2: Scanning electron micrographs for cervical buccal enamel showing.F: SG4 showing a globule like deposits (blue arrows) scattered on the surface of the lesion giving a rough appearance and erosive defects still exit (red arrows) ( $\mathrm{x} 4000)$. 


\section{Statistical analysis}

The mean surface Ca \& $\mathrm{P}$ wt\% in C-vewashigher than that in $\mathrm{C}+$ ve group. However mean surface $\mathrm{C}$ wt $\%$ in $\mathrm{C}+$ ve group was higher than in $\mathrm{C}$-ve group .These differences were statistically highly significant. There was also statistically significant difference between mean surface $\mathrm{Ca} / \mathrm{P}$ ratio in $\mathrm{C}$-ve and $\mathrm{C}+$ ve group as shown in (Figure 3A).

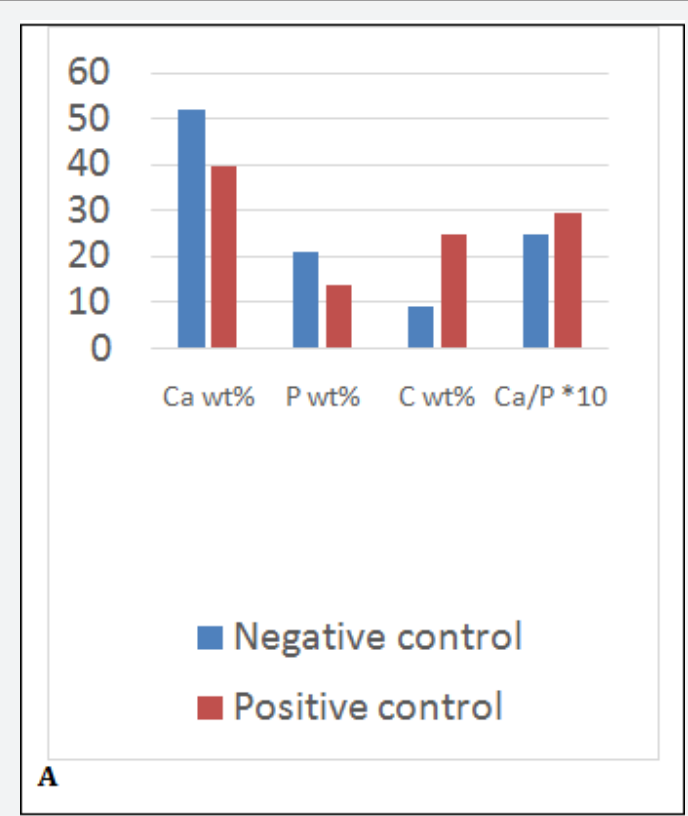

Figure 3: A: Bar chart representing the mean $\mathrm{Ca}, \mathrm{P}$ and $\mathrm{C}$ wt $\%$ as well as $\mathrm{Ca} / \mathrm{P}$ for $\mathrm{C}$-ve and $\mathrm{C}+\mathrm{ve}$.

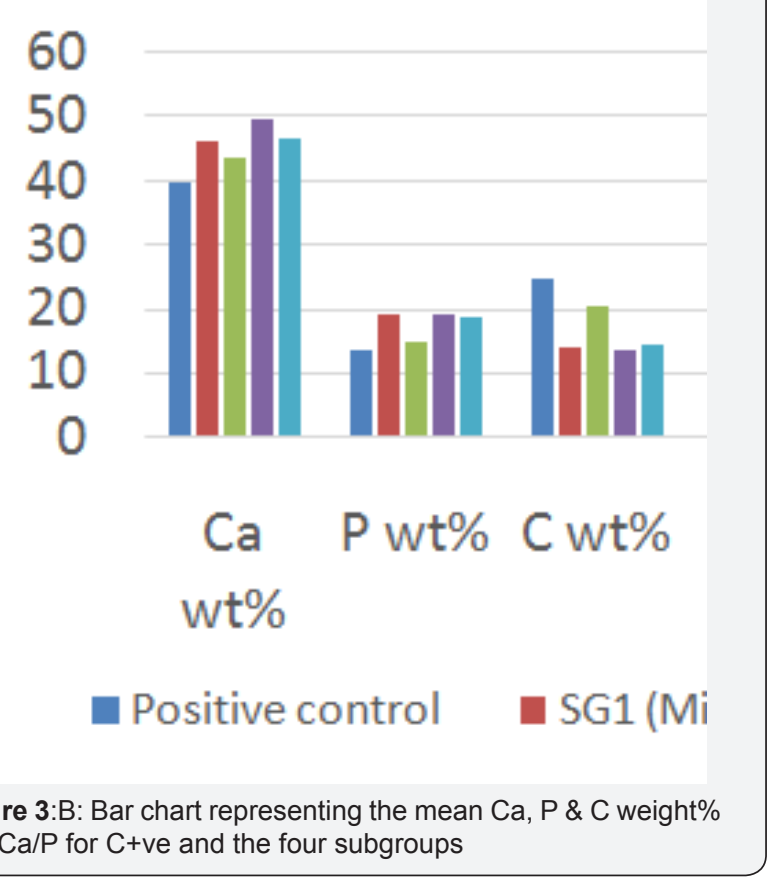

Figure 3:B: Bar chart representing the mean $\mathrm{Ca}, \mathrm{P} \& \mathrm{C}$ weight\% and $\mathrm{Ca} / \mathrm{P}$ for $\mathrm{C}+\mathrm{ve}$ and the four subgroups
There were significance differences between the different beverages regarding the change in mean surface $\mathrm{Ca}, \mathrm{P}$ and $\mathrm{C}$ wt $\%$. Also, all subgroups showing increase in mean $\mathrm{Ca}$ and $\mathrm{P}$ contents and decrease in $\mathrm{C}$ content compared to $\mathrm{C}+\mathrm{ve}$. SG3 showing the highest mean Ca wt\% followed by SG4 then SG1 and the lowest value was for SG2. SG3 showing the highest mean P wt\% followed by SG1 then SG4 and the lowest value was for SG2. SG2 showing the highest mean $\mathrm{C}$ wt\% followed by SG4, then SG1 and SG3 respectively. Mean $\mathrm{Ca} / \mathrm{P}$ ratio was highest in SG2 compared to other groups as shown in (Figure 3B).

\section{Discussion}

Tooth structure undergoes continuous remineralization and demineralization in the oral environment. The ratio between demineralization and remineralization determines the hardness and strength of the tooth structure. Remineralization is the natural repair process of restoring minerals again in the form of mineral ions to the hydroxyapatite's latticework structure. Demineralization occurs at a low $\mathrm{pH}$ when the oral environment is under saturated with mineral ions, relative to a tooth's mineral content Hemagaron et al. [16], 2014.

Soft drinks and carbonated beverages show erosive effects on tooth substance Lussi et al. [3], 2004. On the other hand, dairy products show remineralizing effect Vashisht et al. [17], 2010. Recently, people drink planet based milk products instead of bovine milk especially for those have lactose intolerance syndrome. The present study aimed to evaluate the different effects of bovine and some plant based milk products on dental enamel preceded by exposure to Coca Cola ${ }^{\circledR}$ beverage.

The study was applied to cervical $1 / 3$ of enamel because it is the most affected part as reported by Takahashi et al. [18], 2008. His study was carried out to illustrate the difference in histology and elemental composition of the cervical enamel among human permanent teeth. He reported that the cervical enamel are less calcified and include more organic substances than the cuspal enamel, as the Ca and $\mathrm{P}$ contents were significantly lower. This also is coincident with El-Zainy et al. [15], 2012 who studied the effect of some carbonated beverages on enamel of human premolars using light microscope and scanning electron microscope, their results revealed that enamel affection for a given beverage was maximum at the cervical third and minimal in the occlusal.

Coca Cola ${ }^{\circledR}$ as an example for soft drink was used to induce erosion in the current study because of its great erosive effect as reported by El-Zainy et al. [15], 2012 and Yamamoto et al. [19], 2013 who concluded that Coca-Cola ${ }^{\circledR}$ had more erosive potential than spirit $\circledast$ and Miranda orange $®$.

In our study, the immersion of samples in Coca Cola $\AA$ beverages was 25 hours .The model allows for observation of demineralization within a reasonable time period as designed by Ehlen et al. [14], 2008 who studied the effect of some Acidic beverages on Extracted teeth by polarized light microscope and 
conclude that beverages available for consumption in the United States have the potential to erode both enamel and root surfaces. The Coca-Cola ${ }^{\circledR}$ was replaced at the end of each cycle (5 hours) due to the increase in its PH as reported by Ehlen et al. [14], 2008 and El-Zainy et al. [15], 2012 who recorded an increase in the Coca-Cola ${ }^{\circledR}$ PH after 5 hours from 2.37 to 2.41 .

In milk groups, the teeth had been immersed in a beaker filled with the corresponding milk type for $50 \mathrm{hrs}$ this time was selected based on what had been done by McDougall [10], 1977. Replacement of the milk was done every 2 hours which is the safe period before milk deterioration as milk is one of the potentially hazardous foods. The food safety standards specify that potentially hazardous foods must be stored, displayed and transported at safe temperatures to minimize multiplication of food bacteria. However, you can also use time, rather than temperature, to keep food safe. This method is explained under "The 2 hour/4 hours guide which provides guidance on how long this type of food can be held safely at room temperature. According to this guide, it is safe to keep potentially hazardous food at room temperature for 2 hours, and then you have to return it to refrigerator for a second use later or insure it is used before the 4 hours limit is up NSW Food Authority [20], 2015.

The sample in this study was an intact enamel of sound human premolars as it make the study more realistic and predicting the possible effects of beverage's components. However, most of the in vitro studies used bovine enamel since it is considered a suitable substitute for human enamel Zero [1], 1996 but there are structural differences between bovine and human enamel. Bovine enamel is more porous than human enamel. Therefore it is less resistant to acid diffusion Meurman et al. [21], 1996.

In the present study, the use of artificial saliva as a control medium is not included because it may alter the results as it was reported by Buzalaf et al. [22], that saliva has a remineralization ability due to its super saturation with $\mathrm{Ca}, \mathrm{P}$ and $\mathrm{F}$ necessary for remineralization and the authors concluded that saliva is the most important biological factor affecting the progression of dental erosion.

In our study, the use of EDAX analysis was used as a most suitable experimental tool for detecting the quantities of studied elements in localized areas of enamel. It analyzes the wt $\%$ of an element on a few cubic microns in a non-destructive way and correlates the distribution of various elements to the histological structure of the tissue Samuel SM [23], 2001.

In the current study, the Coca-Cola $₫$ beverage effect detected by SEM on the morphology of the enamel surface (the cervical third of the buccal surface) converted it into defective surface and removed a layer of the surface. This was in accordance with a morphometric study done by Nabil et al. [24], 2012 to determinethe thickness of the affected band in the outer enamel layer at the occlusal and cervical thirds after immersion of the teeth in Coca-Cola $\AA$ beverage for $25 \mathrm{~h}$. Their results revealed a reduction in enamel thickness at both thirds. There is a correlation between weight loss of eroded enamel sections and both $\mathrm{pH}$ and titratable acidity Jensdottir et al. [25], 2005.

In the present study, SEM examination of control positive group revealed irregular enamel surface with some evidence of erosive lesions, areas of ill-defined enamel structure and apparently observed irregular grooves of variable length. This also is coincident with El-Zainy et al. [15], 2012 who studied the effect of Coca-Cola ${ }^{\circledR}$ on cervical third of buccal enamel surface by SEM.

The current study, SEM examination results of different milk groups revealed different patterns of white or light deposits which identified by remineralizing deposits. SEM examination of expermintal SG1 (bovine milk group), revealed mineralized sporadic globular areas over the erosive enamel. Our results were in agreement with those of Arnold et al. [26], 2003, who correlated the remineralizing effect of milk to the absorption of its Ca and $\mathrm{P}$ contents to the enamel surface and the adsorption of milk proteins on the surface. This also came in accordance with Jayarajan et al. [27], 2011 who attempted the efficacy of casein phosphopeptideamorphous calcium phosphate (CPP-ACP) in remineralizing enamel surface on which artificial caries had been created.

Examination of SG2 (soy milk) showed more irregular surface with few mineralized deposits lining some of the irregularities. These irregularities had been reported by Nabil et al. [24], 2016 who studied the effect of soy milk on human enamel premolars samples by SEM. SG3 (almond milk), in this study, revealed almost regular smooth enamel surface with diffused mineralized deposits with no obvious cracks, and SG4 (oat milk) revealed sporadic globular pattern of mineralized deposits on the enamel surface fill the irregularities of the enamel.

The present study revealed the cumulative effect of milk on enamel surface morphology and chemical components after immersion in milk for 50 hours. So the mineralizing effect of milk was very clear as observed by SEM examination. However, Amoras [28], 2012 couldn't detect any remineralizing effect or increase in micro hardness of enamel exposed to milk for 4 Minutes, which is very short exposure time in comparison to the present study. This variation may be attributed to what had been reported by West NX [29], 2000 that the frequencies of application and exposure time are important factors affecting the morphological changes on enamel surface.

The present study showed that after immersion in Coca-Cola ${ }^{\circledR}$ beverage, there was a significant increase in the $\mathrm{C} w \mathrm{t} \%$ according to EDAX results correlated to significant decrease in $\mathrm{P}$ content which was also reflected on SEM photos as areas of defect. as it is known that the carbonate may substitute $\mathrm{OH}$ or $\mathrm{P}$ in the apatite lattice so increase $\mathrm{C}$ content reflects the decrease in enamel hardness Xu C et al. [30], 2012. Ca content also significantly decreased, due to the release of Ca from the enamel surface as a result of surface hydroxyapatite destruction caused by the Coca-Cola ${ }^{\circledR}$ beverage. 
Control samples that were in area of normal enamel that revealed less $\mathrm{C}$ and high $\mathrm{Ca}$ and $\mathrm{P}$ contents according to EDAX results were turned to an area of demineralized enamel had increase $\mathrm{C}$ and decreased $\mathrm{Ca}$ and $\mathrm{P}$ contents.

After immersion in bovine milk (SG1) there was a significant increase in $\mathrm{Ca} / \mathrm{P}$ ratio. This increase may be due to the Ca content in bovine milk. Also, there was a significant decrease in $\mathrm{C}$ level. The decrease in $\mathrm{C}$ and increase in Ca wt\% reflect an increase in the enamel hardness and a decrease in its solubility $\mathrm{Xu} C$ et al. [30], 2012.

In the current study, following the immersion in soy milk (SG2), there was a decrease in C content with an increase in the Ca and $\mathrm{P}$ content but it was less than $\mathrm{Ca}$ and $\mathrm{P}$ contents in the other expermintal groups. These changes represent remineralization after immersion in Coca Cola which may be explained by the presence of $\mathrm{Ca}$ in its content. This was in a disagreement with the study of Vongsavan et al. [31], 2012 who concluded that soy milk gave no protection against dental erosions and has no remineralizing effect on enamel erosions caused by chlorinated water. This conflict could be attributed to the fact that authors soaked their teeth specimen in soy milk with Ca for 20 minutes before they soaked it in chlorinated water for 96 hours. This may be a short exposure time in comparison to the exposure time of the present study which was 50 hours; this may explain why soy milk has no remineralizing effect in their study.

Ternary diagram showing a very little move of the content between $\mathrm{C}+\mathrm{ve}$ and soy milk, they were almost located in the same area of C, Ca \& P contents. After immersion in almond milk (SG3) there was a significant increase in $\mathrm{Ca} / \mathrm{p}$ ratio and a significant decrease in C level.

The highly mineralized effect of almond milk may be because it actually contains $\mathrm{Ca}$, it is one of the best $\mathrm{Ca}$ - containing alternatives, boasting $45 \%$ of the daily values per cup as mentioned by Bedwell [32], 2015.

Immersion of erosive enamel in oat milk (SG4) in this study showed a significant increase in $\mathrm{Ca} / \mathrm{p}$ ratio. This increase may be due to the high Ca content in oat milk. Oat milk contains $36 \%$ of the RDA for Ca, while one serving of whole milk contains $28 \%$ Elsass [33], 2014. Also, there was a significant decrease in C level.

With comparing the effect of different milk beverages on the chemical profile of the erosive enamel surface (statistically), it was observed that the immersion in almond milk showed the best mineralized effect followed by oat and bovine milk and the soy milk showed the less mineralized effect. Also the morphological mineralized effect revealed by SEM, showed that the almond milk have the more diffused mineralized pattern followed by oat milk and bovine milk and the less mineralized deposite were belong the soy milk.

Finally, this study was in vitro study not being a representative of the in-vivo condition in which the oral cavity contains the protective saliva with its minerals. Also it was a relative study, the actual change in enamel hardness and enamel thickness was not estimated. In this study, the effect of some plant based milk (soy, almond and oat) on enamel surface were detected but its effect on other oral cavity tissues are unknown, so further studies on the effect of these beverages on deeper enamel layer and on other oral cavity soft tissues are highly recommended with concern to the oral environment.

\section{Conclusions}

A. The exposure to Coca Cola ${ }^{\circledR}$ beverage significantly decrease calcium and phosphorous levels of enamel surface and altered enamel surface morphology.

B. When demineralized enamel was followed by bovine, soy, almond or Oat milk exposure, a significant increase in calcium and phosphorous levels was recorded.

C. Almond milk showed better results than other types of milk used concerning Ca and P levels as well as surface morphological alternations.

D. Soy milk showed the least enamel remineralizing effect of all types of milk used.

\section{References}

1. Zero DT (1996) Etiology of dental erosion-extrinsic factors. Eur J Oral Sci 104(2): 162-177.

2. Magalhaes AC, Rios D, Delbem AC, Buzalaf MA, Machado MA (2007) Influence of fluoride dentrifice on brushing abrasion of eroded human enamel: an in situ/ ex vivo study. Caries Res 41(1): 77-79.

3. Lussi A, Jaeggi T, Zero D (2004) The role of diet in the etiology of dental erosion. Caries Res 38(1): 34-44.

4. Lussi A, Jaeggi (2006) Chemical factors. Monogr Oral Sci 20: 77-87.

5. Houpt, Simon (2011) Apple cracks Interbrand's best global brands top 10 list. Globe and Mail, Canada.

6. Gedalia I, Dakuar A, Shapira L, Lewinstein I, Goultschin J, et al. (1991) Enamel softening with coca-cola and re-hardening with milk or saliva. Am J Dent 4(3): 120-122.

7. Lewinstein I, Ofek L, Gedalia I (1993) Enamel rehardening by soft cheeses. Am J Dent 6(1): 46-48.

8. Reynolds EC, Cai E (1999) Advances in enamel remineralization: Anticariogenic casein phosphopeptide-amorphous calcium phosphate. J Clin Dent 10: 86-88.

9. Morgan MV, Adams GG, Bailey DL, Tsao CE, Fischman SL, et al. (2008) The anticariogenic effect of sugar-free gum containing CPPACP nanocomplexes on approximal caries determined using digital bitewing radiography. Caries Res 42(3): 171-184.

10. McDougall WA (1977) Effect of milk on enamel demineralization aremineralization in vitro. Caries Res 11(3): 166-172.

11. Mor BM, Rodda JC (1983) In vitro remineralization of artificial carieslike lesions with milk. N Z Dent J 79: 10-15.

12. Anonymous: Plant-based dairy alternatives on the rise. Food Product Design.

13. Latif $R$ (2012) Dairy alternative beverage market reached $\$ 1.33$ billion in 2011. 
14. Ehlen LA, Marshal TA, Qian F, Wefel JS, Warren JJ (2008) Acidic beverages increase the risk of in vitro tooth erosion. Nutr Res 28(5): 299-303.

15. El-Zainy MA, Halawa AM, Rabea AA (2012) The effect of some carbonated beverages on enamel of human premolars (Scanning and Light Microscopic Study). Journal of American science 8 (3): 632-643.

16. Hemagaran G, Neelakantan P (2014) Remineralization of the Tooth Structure-The Future of Dentistry. International Journal of Pharm Tech Research 6 (2): 487-449.

17. Vashisht R, Kumar A, Indira R, Srinivasan MR, Ramachandran S (2010) Remineralization of early enamel lesions using casein phosphopeptide amorphous calcium phosphate: an ex vivo study. ContempClin Dent 1(4): 210-213.

18. Takahashi M, Goto S, Mori K, Mataga I (2008) Difference of histology and elemental composition of the cervical enamels among human permanent teeth. Frontiers of Materials Science in China 2(4): 437-440.

19. Yamamoto ETC, Vanderlei A, Amaral R, Di Nicolo R, Rocha JC, et al (2013) Influence of three types of drinks on the surface of human dental enamel: in vitro study. Rev Gaúcha Odontol 61(1): 41-46.

20. NSW Food Authority (2015) Food Authority: 4 hour - 2 hour.

21. Meurman JH, Ten Cate JM (1996) Pathogenesis and modifying factors of dental erosion. Eur J Oral Sci 104(2): 199-206.

22. Buzalaf MA, Hannas AR, Kato MT (2012) Saliva and dental erosion. J Appl Oral Sci 20(5): 493-502.

23. Samuel SM, Rubinstein C (2001) Microhardness of enamel restored with fluoride and non-fluoride releasing dental materials. Braz Dent J 12: 35-38.

24. Nabil M, El-Zainy MA, Rabea AA (2016) Comparative study of the possible effect of cow milk and soy milk on enamel of human premolar samples. Egyptian Dental journal 62: 2697-2719.
25. Jensdottir T, Bardow A, Holbrook P (2005) Properties and modification of soft drinks in relation to their erosive potential in vitro. J Dent 33(7): 569-575.

26. Arnold WH, Cerman M, Neuhaus, K, Gaengler P (2003) volumetric assessment and quantitative element analysis of the effect of fluoridated milk on enamel demineralisation. Arch Oral Biol 48(6): 467-473.

27. Jayarajan J, Janardhanam P, Jayakumar P, Deepika (2011) Efficacy of CPP-ACP and CPP-ACPF on enamel remineralization-An in vitro study using scanning electron microscope and DIAGNOdent. Indian J Dent Res 22(1): 77-82.

28. Amoras DR, Corona SA, Rodrigues Al Jr, Serra MC (2012) Effect of Beverages on Bovine Dental Enamel Subjected to Erosive Challenge with Hydrochloric Acid. Braz Dent J 23(4): 367-372.

29. West NX, Hughe JA, Addy M (2000) Erosion of dentine and enamel in vitro by dietary acids: the effect of temperature, acid character, concentration and exposure time. J Oral Rehabil 27(10): 875-880.

30. Changqi XU, Rachel R, Gorski JP, Yong W, Walker MP (2012) The distribution of carbonate in enamel and its correlation with structure and mechanical properties. J Mater Sci 47(23): 8035-8043.

31. Vongsavan K, Surarit R, Rirattanapong P (2012) Effectiveness of soy milk with calcium on bovine enamel erosions after soaking in chlorinated water. Southeast Asian J Trop Med Public Health 43(5): 1292-1296

32. Bedwell SJ (2015) Almond, Soy, Rice and Other Milks: The Nutrition Comparison.

33. Elsass P (2014) What Are the Benefits of Oat Milk.

\section{Your next submission with Juniper Publishers will reach you the below assets}

- Quality Editorial service

- Swift Peer Review

- Reprints availability

- E-prints Service

- Manuscript Podcast for convenient understanding

- Global attainment for your research

- Manuscript accessibility in different formats

( Pdf, E-pub, Full Text, Audio)

- Unceasing customer service

Track the below URL for one-step submission https://juniperpublishers.com/online-submission.php 